\title{
The STIB score: a simple clinical test to predict clopidogrel resistance
}

\author{
Delphine LEGRAND ${ }^{1}$, MD; Emanuele BARBATO ${ }^{2}$, MD; Patrick CHENU ${ }^{3}$, MD; Julien MAGNE ${ }^{4}$ PhD; \\ Mathias VROLIX ${ }^{5}$, MD; William WIJNS ${ }^{2}, \mathrm{MD}, \mathrm{PhD}$; Victor LEGRAND ${ }^{4}, \mathrm{MD}, \mathrm{PhD}$; \\ on behalf of the STIB investigators
}

${ }^{1} \mathrm{CHR}$ Citadelle Liège, Belgium; ${ }^{2}$ Cardiovascular Center Aalst OLV-Clinic, Belgium; ${ }^{3} \mathrm{CHU}$ Mont Godinne, Yvoir, Belgium; ${ }^{4} \mathrm{CHU}$ de Liège, Belgium; ${ }^{5}$ St. Jan Ziekenhuis Genk, Belgium.

Background High platelet reactivity (HPR) to clopidogrel is associated with an increased risk of ischaemic complications during and after coronary interventions and concerns up to $50 \%$ of patients undergoing $\mathrm{PCl}$.

Aim of the study The aim of the study was to identify patients with HPR to clopidogrel using bedside clinical information obtained in the Stent Thrombosis In Belgium (STIB) trial.

Methods Data on platelet reactivity using the VerifyNow point-of-care assay were obtained in 844 patients undergoing $\mathrm{PCl}$ for stable coronary artery disease 12 to 24 hours after a 600-mg loading dose of clopidogrel was given. Demographic, clinical and baseline routine biological tests were obtained and compared with P2Y12 reaction units (PRU). Patients with PRU > 230 (HPR) were considered as non-responders to clopidogrel.

Results HPR was observed in 424/844 pts. Age, weight, body mass index (BMI), HPR to aspirin, diabetes, renal failure (MDRD $<60 \mathrm{ml} / \mathrm{min}$ ), haemoglobin $(\mathrm{Hb})$, haematocrit, fibrinogen, glycaemia and glycated haemoglobin were associated with HPR to clopidogrel. In multivariate analysis, only Hb (OR: 0.77), BMI (OR: 1.06) and diabetes (OR: 1.62) emerged as independent risk factors. $\mathrm{Hb}<13.9 \mathrm{~g} / \mathrm{dl}, \mathrm{BMI}>28 \mathrm{~kg} / \mathrm{m}^{2}$ and presence of diabetes were equally associated to predict HPR and can be added to derive a simple score to predict clopidogrel resistance.

Although $38.5 \%$ of patients without a single clinical predictor still have HPR, 2/3 patients with 2 or 3 risk factors are resistant to clopidogrel.

Conclusions STIB HPR score allows identification of patients with a high probability of resistance to clopidogrel based on diabetes, $\mathrm{Hb}<13.9 \mathrm{~g} /$ $\mathrm{dl}$ and $\mathrm{BMI}>28 \mathrm{~kg} / \mathrm{m}^{2}$. This bedside clinical test could be useful for the identification of patients in whom another P2Y12 inhibitor should be recommended before and after $\mathrm{PCl}$.

Keywords Clopidogrel resistance-VerifyNow ${ }^{\circledR}$ - coronary disease - ischaemic events - bleeding.

\section{INTRODUCTION}

Clopidogrel and acetylsalicylic acid are the cornerstone treatment of acute coronary syndromes and percutaneous coronary interventions (PCI). High platelet reactivity (HPR) after clopidogrel loading is defined as clopidogrel resistance and linked to adverse ischaemic events ${ }^{1}$. Although clinical value and impact of individually

\section{Address for correspondence:}

Delphine Legrand, MD,

Service de Cardiologie, CHR Liège, Bvd $12^{\circ}$ Ligne, 4000 Liège, Belgium.

E-mail: delphine.legrand@chrcitadelle.be

Received 11 November 2014, revision accepted for publication adjusted dosage according to platelet reactivity are still debated, treatment adaptations are proposed to overcome HPR to clopidogrel by doubling the current clopidogrel dosage or by switching to another more potent agent such as prasugrel or ticagrelor ${ }^{2}$.This strategy is recommended for patients with unstable angina or non-ST-elevation myocardial infarction as a class IIb recommendation ${ }^{3}$.

One-month results of the STIB trial showed that HPR was not predictive of early ischaemic events in patients with stable angina undergoing planned PCI, although HPR to clopidogrel was observed in $50 \%$ of these patients using the point-of-care VerifyNow ${ }^{\otimes}$ test ${ }^{4}$. These data contrast with the observations made in patients undergoing PCI for unstable coronary syndromes ${ }^{5}$. However, despite absence of early clinical benefit in the STIB trial, a late negative impact of HPR to clopidogrel on the development 
of stent thrombosis or recurrent ischaemic events has been documented ${ }^{1}$. Conversely, prescription of a drug with no significant biological effect may be questioned. Because real-life platelet reactivity testing is limited by test cost and availability, it is of paramount importance to easily identify patients unresponsive to clopidogrel at bedside. We therefore performed statistical analysis of baseline clinical and biological factors of the patients enrolled in the STIB trial in order to derive a simple clinical score associated with clopidogrel resistance.

\section{METHODS}

\section{Study population}

From March 2008 to October 2010, 891consecutive patients undergoing coronary angioplasty for stable angina pectoris were screened with platelet function testing from five sites in Belgium. All patients were treated with $500 \mathrm{mg}$ acetylsalicylic acid and $600 \mathrm{mg}$ clopidogrel, per os, 12 to $18 \mathrm{~h}$ before the intervention.

\section{Study protocol}

PR was measured in the catheterization laboratory before PCI by the Point-of-care VerifyNow test with P2Y12 cartridge to test the degree of platelet inhibition to clopidogrel and with the aspirin cartridge to assess degree of platelet inhibition to aspirin (Accumetrics Inc., San Diego, CA, USA). Measures of antiplatelet effect of clopidogrel are expressed as P2Y12 reaction units (PRU). High PR has been defined in numerous studies as $>230 \mathrm{PRU}^{6,7}$. Measures of the antiplatelet effect of aspirin are expressed as aspirin reaction units (ARU). ARU values less than 550 indicate that platelets are inhibited by aspirin. Operators were blinded to the PRU and ARU measurements.

Among the 891 eligible patients, PRU was obtained in 882 and ARU in 852 patients. Both PRU and ARU values were available in 848 patients.

Baseline demographic and clinical data were prospectively recorded according to a standard data base ${ }^{4}$. Venous blood samples were collected in each patient at admission. Blood cells count, fibrinogen, us CRP, kidney function, glycaemia, glycated haemoglobin, creatine kinase and troponin were analysed. Complete data sets were available for 844 patients.

\section{Statistical analysis}

Continuous variables are presented as mean value \pm standard deviation. Categorical data are reported as frequencies and percentages. Differences in continuous variables were compared by one-way analysis of variance. Comparisons of categorical variables were tested by the $\chi^{2}$ test or Fisher's exact test, as appropriate. Multivariate stepwise logistic regression was used to identify independent predictors of the occurrence of HPR (PRU > $230 \mathrm{U}$ or ARU $>550 \mathrm{U}$ ). The variables (demographic, clinical, and laboratory) entered in the model were selected using stepwise regression analysis with an entry criterion of $P<0.10$. Variables significantly associated with HPR in multivariate analysis were used to build a logistic regression model. The $\beta$ coefficient of each variable was determined and allows construction of a simple score. All analyses were performed with the SPSS software version 13.0 (SPSS Inc., Chicago, Illinois).

\section{RESULTS}

The baseline characteristics of the 844 patients enrolled in the STIB trial with complete clinical and biological data are detailed in table 1 .

We found that $50.2 \%(424 / 844)$ of the patients had clopidogrel resistance (PRU > 230) and 7\% had aspirin resistance. Clinical and demographic characteristics, medications and laboratory findings of clopidogrel resistant patients are given in table 2 .

\section{Factors associated with HPR}

Clinical factors significantly associated with HPR on clopidogrel are increasing age, weight and BMI, diabetes and renal failure.

Biological factors associated with clopidogrel resistance are anaemia (low haematocrit, low haemoglobin), fibrinogen, glycaemia, glycated haemoglobin, and resistance to aspirin $(A R U \geq 550)$.

In multivariate analysis, haemoglobin (OR: 0.77), BMI (OR: 1.06) and diabetes (OR: 1.62) remain significantly associated with clopidogrel resistance.

Resistance risk (PRU $\geq 230$ ) was best correlated with diabetes: relative risk: 1.58 (1.27 to 1.98 ) (sensitivity: $61 \%$, specificity: $54 \%)$, haemoglobin $<13.9 \mathrm{~g} / \mathrm{dl}$ : relative risk: 1.45 (1.24 to 1.69 ) (sensitivity: 60\%, specificity: $57 \%$ ), and BMI $>28 \mathrm{~kg} / \mathrm{m}^{2}$ : relative risk: 1.38 ( 1.17 to 1.63) (sensitivity: 59\%, specificity: $55 \%$ ).

No association was found between HPR and diabetes duration or the class of antidiabetic medication among the 239 diabetes patients.

\section{Prediction of HPR to clopidogrel (clopidogrel resistance)}

Anaemia, BMI and diabetes were significantly and equally associated with clopidogrel resistance (in logistic regression equation). As such, these three factors act as independent variables with similar weight to predict 
clopidogrel resistance risk. Because of the similar diagnostic performance, they may be used to derive a simple prediction score of HPR to clopidogrel. Probability for HPR to clopidogrel is $77.8 \%$ in patients with diabetes, BMI $>28 \mathrm{~kg} / \mathrm{m}^{2}$ and haemoglobin $<13.9 \mathrm{~g} / \mathrm{dl}(\mathrm{n}=56$, $13 \%$ ) and $62.6 \%$ of patients with at least 2 of these characteristics $(n=134,31.6 \%)$. Conversely, probability of HPR is lower in patients without or with only one of these characteristics (38.5 and $44.1 \%$, respectively) (figure 1).

\section{DISCUSSION}

The prospective multicentre STIB study helps us to identify simple clinical and biological factors associated with clopidogrel resistance in patients undergoing PCI for stable angina pectoris and pretreated according to current standard with $500 \mathrm{mg}$ aspirin plus $600 \mathrm{mg}$ clopidogrel at least 12 hours before the procedure.

Incidence of clopidogrel hypo-responders (50.2\%) found in the STIB trial is slightly higher than in the multicentre GRAVITAS trial (40.6\%) using the same hypo-responsiveness definition ${ }^{7}$. Platelet reactivity was assessed before PCI in the STIB trial, while it was measured 12 to $24 \mathrm{~h}$ post PCI in the GRAVITAS trial. The higher HPR found in the STIB study may be related to the pharmacokinetics of clopidogrel which is a prodrug that may require more than $12 \mathrm{~h}$ in some patients to be transformed into an active metabolite.

In this population of patients with stable angina pectoris, we found that response to clopidogrel diminishes with advancing age, increasing body mass index, renal failure, diabetes, poor glycaemic control, low haemoglobin, high fibrinogen values and HPR to aspirin. Numerous studies have shown that responsiveness to clopidogrel is influenced, not only by pharmacogenetic factors linked to CYP enzymes, but also by clinical factors such as age, diabetes, renal failure, obesity, anaemia or elevated fibrinogen ${ }^{8,9}$.

Results of trials conducted in patients with stable angina pectoris diverge from those reported in studies performed among patients presenting with acute and unstable coronary disease which showed an association between clopidogrel resistance and adverse ischaemic events. Lack of association between HPR to clopidogrel and clinical outcomes in stable coronary disease, highlight a lower need for optimal platelet inhibition in low risk patients ${ }^{10}$. This conclusion is reinforced by the absence of incremental protection with more potent platelet inhibition (through higher clopidogrel doses or prasugrel $)^{11}$ or with the extension of dual antiplatelet therapy beyond one year after stenting in stable conditions ${ }^{12}$. In these patients, adverse events are more likely
Table 1 Demographic features, platelets reactivity, cardiovascular risk factors, medication use, laboratory findings in global population

\begin{tabular}{|c|c|}
\hline Age & $66 \pm 10$ \\
\hline Male sex, $n(\%)$ & $638(75)$ \\
\hline BMI, $\mathrm{kg} / \mathrm{m}^{2}$ & $27 \pm 4$ \\
\hline PRU value (unit) & $221 \pm 101$ \\
\hline ARU value (unit) & $434 \pm 70$ \\
\hline HPR on clopidogrel, PRU > $230 \mathrm{U}, \mathrm{n}(\%)$ & $424(50)$ \\
\hline HPR on aspirin, $A R U>550 \mathrm{U}, \mathrm{n}(\%)$ & $57(7)$ \\
\hline HPR on clopidogrel and aspirin, $n(\%)$ & $34(4)$ \\
\hline Hypertensive (PA $\geq 140 / 90 \mathrm{mmHg}$ ), n (\%) & $547(65)$ \\
\hline $\mathrm{LDL} \geq 135 \mathrm{mg} / \mathrm{dl}, \mathrm{n}(\%)$ & $614(73)$ \\
\hline GFR (MDRD formula) < $60 \mathrm{ml} / \mathrm{min}$ ), $\mathrm{n}(\%)$ & $176(21)$ \\
\hline Diabetes, n (\%) & $239(28)$ \\
\hline Diabetes with insulin, $n$ (\%) & $42(18)$ \\
\hline with OAD, n (\%) & $169(71)$ \\
\hline on diet, n (\%) & $5(2)$ \\
\hline Unknown diabete (Hba1c $\geq 6.5 \%$ ), n (\%) & $23(10)$ \\
\hline Diabete duration (years) & 11 \\
\hline Smoking, n (\%) & $459(54)$ \\
\hline active, $\mathrm{n}(\%)$ & $192(23)$ \\
\hline previous, n (\%) & $267(32)$ \\
\hline Ischaemic cardiopathy, n (\%) & $528(63)$ \\
\hline Stable coronary disease, $\mathrm{n}(\%)$ & $85(10)$ \\
\hline Myocardial infarction, n (\%) & $213(25)$ \\
\hline Heart failure, $\mathrm{n}(\%)$ & $8(1)$ \\
\hline Percutaneous coronary intervention, $n$ (\%) & $338(40)$ \\
\hline Stroke, $n(\%)$ & $46(5)$ \\
\hline Coronary bypass, n (\%) & $88(10)$ \\
\hline Peripheral arterial disease n (\%) & $94(11)$ \\
\hline Valvulopathy, $\mathrm{n}(\%)$ & $30(4)$ \\
\hline Haemoglobin, g/dl & $13.92 \pm 1.60$ \\
\hline Haematocrit, $\%$ & $41 \pm 4$ \\
\hline Leukocyte count, $10^{3} / \mathrm{mm}^{3}$ & $7769 \pm 2211$ \\
\hline Platelet count, $10^{3} / \mathrm{mm}^{3}$ & $246 \pm 77$ \\
\hline Fibrinogen, mg/dl & $360 \pm 102$ \\
\hline uCRP, mg/dl & $2.87 \pm 6.14$ \\
\hline Glycaemia, mg/dl & $109 \pm 39$ \\
\hline Hba1c, \% & $6.1 \pm 0.9$ \\
\hline Creatinin, mg/dl & $1.01 \pm 0.42$ \\
\hline Aspirin on chronic treatment, $\mathrm{n}(\%)$ & $745(88)$ \\
\hline Thienopyridin on chronic treatment, $n(\%)$ & $327(39)$ \\
\hline$A V K, n(\%)$ & $5(0.6)$ \\
\hline Beta blocker, n (\%) & $513(61)$ \\
\hline ACE-i, n (\%) & $306(36)$ \\
\hline ARB, $n(\%)$ & $116(14)$ \\
\hline Statin, n (\%) & $581(69)$ \\
\hline Fibrate, n (\%) & $39(5)$ \\
\hline
\end{tabular}

Abbreviations: BMI: body mass index, PRU: P2Y12 reaction unit, ARU: aspirin reaction unit, HPR: high platelet reactivity, LDL: low-density lipoprotein, GFR: glomerular filtration rate, OAD: oral antidiabetic, HbA1c: haemoglobin A1c, u CRP: ultrasensitive C reactive protein, AVK: antivitamin K, ACE-l: angiotensin-converting enzyme inhibitor, ARB: angiotensin receptor blocker. 
Table 2

\begin{tabular}{|c|c|c|c|}
\hline Characteristics & $\begin{array}{c}\text { Clopidogrel sensitive } \\
\text { PRU } \leq 230(n=420) \\
\text { Mean, standard deviation }\end{array}$ & $\begin{array}{c}\text { Clopidogrel resistant } \\
\text { PRU > } 230(n=424) \\
\text { Mean, standard deviation }\end{array}$ & $P$ value \\
\hline Age, years & $64 \pm 11$ & $68 \pm 11$ & 0.001 \\
\hline Male sex, $n(\%)$ & $327(51)$ & $311(49)$ & 0.12 \\
\hline $\mathrm{BMI}, \mathrm{kg} / \mathrm{m}^{2}$ & $27 \pm 4$ & $28 \pm 4$ & 0.001 \\
\hline PRU value (unit) & $137 \pm 64$ & $304 \pm 55$ & 0.001 \\
\hline ARU value (unit) & $422 \pm 64$ & $446 \pm 75$ & 0.001 \\
\hline Aspirin resistant, $A R U \geq 550 \mathrm{U}$ & $23(5)$ & $34(8)$ & 0.14 \\
\hline Hypertensive (PA $\geq 140 / 90 \mathrm{mmHg}$ ), $n(\%)$ & $267(64)$ & $280(66)$ & 0.453 \\
\hline $\mathrm{LDL} \geq 135 \mathrm{mg} / \mathrm{dl}, \mathrm{n}(\%)$ & $310(74)$ & $304(72)$ & 0.491 \\
\hline GFR (MDRD formula) $<60 \mathrm{ml} / \mathrm{min}$ ), $\mathrm{n}(\%)$ & $76(18)$ & $100(24)$ & 0.05 \\
\hline Diabetes, $\mathbf{n}(\%)$ & $92(22)$ & $147(35)$ & 0.001 \\
\hline Diabetes with insulin, $\mathrm{n}(\%)$ & $23(43)$ & $31(57)$ & 0.48 \\
\hline with OAD, n (\%) & $59(36)$ & $106(64)$ & 0.194 \\
\hline on diet, n (\%) & $43(34)$ & $84(66)$ & 0.11 \\
\hline Diabete duration (years) & $10 \pm 8$ & $12 \pm 9$ & 0.43 \\
\hline Smoking, n (\%) & $232(55)$ & $227(54)$ & 0.372 \\
\hline Ischaemic cardiopathy, n (\%) & $274(65)$ & $254(60)$ & 0.109 \\
\hline Stable coronary disease, $\mathrm{n}(\%)$ & $39(9)$ & $46(11)$ & 0.451 \\
\hline Myocardial infarction, $\mathrm{n}(\%)$ & $117(28)$ & $96(23)$ & 0.81 \\
\hline Heart failure, $n(\%)$ & $2(0.5)$ & $6(1)$ & 0.159 \\
\hline Percutaneous coronary intervention, $n(\%)$ & $183(44)$ & $155(37)$ & 0.38 \\
\hline Stroke, $n(\%)$ & $23(5)$ & $23(5)$ & 0.974 \\
\hline Coronary bypass, $\mathrm{n}(\%)$ & $39(9)$ & $49(12)$ & 0.28 \\
\hline Peripheral arterial disease n (\%) & $42(10)$ & $52(12)$ & 0.296 \\
\hline Valvulopathy, $\mathrm{n}(\%)$ & $12(3)$ & $18(4)$ & 0.276 \\
\hline Haemoglobin, g/dl & $14.25 \pm 1.50$ & $13.59 \pm 1.64$ & 0.001 \\
\hline Haematocrit, $\%$ & $42 \pm 4$ & $40 \pm 4$ & 0.001 \\
\hline Leukocyte count, $10^{3} / \mathrm{mm}^{3}$ ) & $7744 \pm 2160$ & $7794 \pm 2263$ & 0.75 \\
\hline Platelet count, $10^{3} / \mathrm{mm}^{3}$ & $248 \pm 84$ & $244 \pm 69$ & 0.49 \\
\hline Fibrinogen, $\mathrm{mg} / \mathrm{dl}$ & $325 \pm 97$ & $369 \pm 103$ & 0.029 \\
\hline uCRP, mg/dl & $2.91 \pm 7.05$ & $2.8 \pm 5.12$ & 0.87 \\
\hline Glycaemia, mg/dl & $105 \pm 36$ & $114 \pm 43$ & 0.006 \\
\hline Hba1c, \% & $6.00 \pm 0.81$ & $6.29 \pm 1.00$ & 0.001 \\
\hline Creatinin, $\mathrm{mg} / \mathrm{dl}$ & $1.02 \pm 0.48$ & $1.01 \pm 0.366$ & 0.95 \\
\hline GFR, $\mathrm{ml} / \mathrm{min}$ & $70 \pm 23$ & $67 \pm 22$ & 0.93 \\
\hline Aspirin on chronic treatment, $\mathrm{n}(\%)$ & $365(89)$ & $363(87)$ & 0.325 \\
\hline Thienopyridin on chronic treatment, $\mathrm{n}(\%)$ & $164(40)$ & $156(37)$ & 0.427 \\
\hline AVK, $n(\%)$ & $1(0)$ & $4(1)$ & 0.186 \\
\hline Beta blocker, n (\%) & $255(62)$ & $246(59)$ & 0.322 \\
\hline ACE-i, n (\%) & $152(37)$ & $147(35)$ & 0.567 \\
\hline ARB, $n(\%)$ & $49(12)$ & $64(15)$ & 0.163 \\
\hline Statin, n (\%) & $282(69)$ & $286(69)$ & 0.909 \\
\hline Fibrate, $\mathbf{n}(\%)$ & $20(5)$ & $18(4)$ & 0.688 \\
\hline
\end{tabular}

Abbreviations: BMI: body mass index, PRU: P2Y12 reaction unit, ARU: aspirin reaction unit, HPR: high platelet reactivity, LDL: low-density lipoprotein, GFR: glomerular filtration rate, OAD: oral antidiabetic, HbA1c: haemoglobin A1c, u CRP: ultrasensitive C reactive protein, AVK: antivitamin K, ACE-l: angiotensin-converting enzyme inhibitor, ARB: angiotensin receptor blocker. 


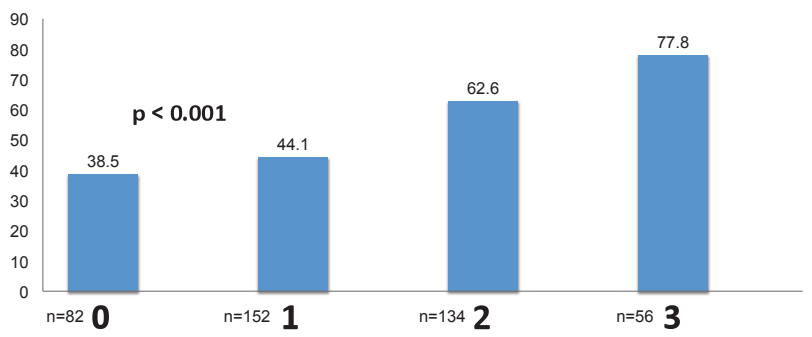

Fig. 1 HPR prevalence according to numbers of risk factors associated with HPR (BMI $>28 \mathrm{~kg} / \mathrm{m}^{2}$, diabetes, $\left.\mathrm{Hb}<13.9 \mathrm{~g} / \mathrm{dl}\right)$.

linked to procedural and clinical conditions (stent length, kidney disease, diabetes, and leukocytosis).

Dual antiplatelet therapy remains the main medical therapy for optimizing stent-related outcomes after PCI and stent placement. It consists of aspirin plus a P2Y12 inhibitor. Selection of P2Y12 inhibitor depends on the patient's first clinical presentation. ACS patients should be treated with ticagrelor or prasugrel, both of which provide superior efficacy compared with clopidogrel but are also associated with increased risk of bleeding. NonACS patients may be treated with clopidogrel ${ }^{13}$.

Our observations highlight that HPR to clopidogrel is present in $50 \%$ of this population, however. Therefore, it may be considered to lower the risk of early and late ischaemic events in those patients using a more potent $\mathrm{P} 2 \mathrm{Y} 12$ inhibitor when risk of bleeding complications is low. Our results suggest that a simple clinical evaluation may help identify individuals with a high probability of HPR to clopidogrel who may benefit from a more potent P2Y12 inhibitor.

Data derived from the STIB trial indeed reveal that combination of three simple parameters $(\mathrm{Hb}<13.9 \mathrm{~g} /$ $\mathrm{dl}, \mathrm{BMI}>28$ and diabetes), the so-called STIB score, allows an excellent risk stratification for HPR to clopidogrel in non-ACS patients. This simple approach may replace routine platelet function or genetic testing which is currently not recommended to tailor antiplatelet therapy after PCI.

Recent data reveal that identification of HPR to clopidogrel may justify treatment adaptation post PCI of nonACS patients. Post hoc analyses of the GRAVITAS trial data show that the lack of late clinical benefit of a higher clopidogrel dosage is linked to the persistence of clopidogrel resistance in $40 \%$ of the patients. Indeed, subgroup analysis of patients who became sensitive with higher clopidogrel dosages showed improved clinical outcome. Recent studies and registries do not erase the doubt, however. Two recent studies showed a lower rate of adverse events with step-by-step dose or drug adjustments ${ }^{14,15}$ while the ARTIC trial, a study designed to mitigate weaknesses of the GRAVITAS trial, demonstrated no benefit ${ }^{16}$.

Thanks to the "STIB score" we may simply enhance our capacity to improve identification of patients with a high risk of clopidogrel resistance (STIB score of $3=\mathrm{HPR}$ in $78 \%$ of patient) without any additional costs in whom an alternative P2Y12 inhibitor could be given. Conversely, it seems reasonable to consider clopidogrel as clinically and economically attractive in patients requiring dual antiplatelet therapy when the STIB score is of 0 or 1 .

Specifically, our study confirms that clopidogrel monotherapy could be non-protective in most obese diabetic patients. Therefore in these patients, either a monotherapy with aspirin or a dual antiplatelet therapy with aspirin plus ticagrelor or prasugrel should be recommended according to the clinical situation and specifically the bleeding risk.

Conversely, patients with STIB score 2 or 3 can be considered as resistant to clopidogrel with a lower risk of bleeding when urgent surgery is planned. This finding could also influence the management of these patient before surgery.

\section{CONCLUSION}

Personalized antiplatelet therapy in non-ACS patients following PCI is an attractive strategy. We first proposed a simple clinical and biological score to predict clopidogrel resistance at bedside, avoiding the use of routine platelet function testing. The STIB score is based on the addition of three parameters: $\mathrm{BMI}>28 \mathrm{~kg} / \mathrm{m}^{2}, \mathrm{Hb}$ $<13.9 \mathrm{~g} / \mathrm{dl}$ and diabetes. Probability of HPR to clopidogrel ranges between 38.5 and $77.8 \%$ according to the presence of one, two or three cumulative factors. It may thus identify patients with high probability of resistance to clopidogrel.

CONFLICT OF INTEREST: none. 


\section{REFERENCES}

1. Brar SS, Ten Berg J, Marcucci R, Price MJ, Valgimigli M, Kim HS, Patti G, Breet NJ, DiSciascio G, Cuisset T, Dangas G. Impact of platelet reactivity on clinical outcomes after percutaneous coronary intervention: a collaborative meta-analysis of individual participant data. J Am Coll Cardiol 2011; 58: 1945-54.

2. Nijjer SS, Davies JE, Francis DP. Quantitative comparison of clopidogrel $600 \mathrm{mg}$ prasugrel and ticagrelor, against clopidogrel $300 \mathrm{mg}$ on major adverse cardiovascular events and bleeding in coronary stenting: synthesis of CURRENT-OASIS-7, TRITON-TIMI-38 and PLATO. Int J Cardiol 2012; 158: 181-5.

3. The Task Force for the Management of Acute Coronary Syndromes (ACS) in patients presenting without Persistent ST-Segment Elevation of the European Society of cardiology (ESC). ESC Clinical Practice Guidelines. Eur Heart J 2011; 32: 2999-3054.

4. Legrand V, Cuisset T, Chenu P, Vrolix M, Martinez C, Dens J, Gach O, Boland J, Claeys MJ, Magne J, Barbato E, Wijns W. Platelet reactivity and cardiovascular events after percutaneous coronary intervention in patients with stable coronary artery disease. The Stent Thrombosis in Belgium (STIB) trial. Eurointervention 2014; 10: 204-11.

5. Matetzky S, Shenkman B, Guetta V, Shechter M, Beinart R, Goldenberg I, Novikov I, Pres H, Savion N, Varon D, Hod H. Clopidogrel resistance is associated with increased risk of recurrent atherothrombotic events in patients with acute myocardial infarction. Circulation 2004; 109: 3171-5.

6. Price MJ, Angiolillo DJ, Teirstein PS, Lillie E, Manoukian SV, Berger PB, Tanguay JF, Cannon CP, Topol EJ. Platelet reactivity and cardiovascular outcomes after percutaneous coronary intervention. A time-dependent analysis of the Gauging Responsiveness with a Verify Now P2Y12 Assay: Impact on the
Thrombosis and Safety (GRAVITAS) trial. Circulation 2011; 124: 1132-7.

7. Price MJ, Berger PB, Teirstein PS, Tanguay JF, Angiolillo DJ, Spriggs D, Puri S, Robbins M, Garratt KN, Bertrand OF, Stillabower ME, Aragon JR, Kandzari DE, Stinis CT, Lee MS, Manoukian SV, Cannon CP, Schork NJ, Topol EJ; GRAVITAS Investigators. Standard-vs high-dose clopidogrel based on platelet function testing after percutaneous intervention: the GRAVITAS randomized trial. JAMA 2011; 305: 1097-105.

8. Angiolillo DJ, Fernandez-Ortiz A, Bernado E, Alfonso F, Macaya C, Bass TA, Costa MA. Variability in individual response to clopidogrel. Clinical implication, management and future perspectives. J Am Coll Cardiol 2007; 49: 1505-16.

9. Angiolillo DJ, Fernandez-Ortiz A, Bernado E, Barrera Ramírez C, Sabaté M, Fernandez C, Hernández-Antolín R, Escaned J, Alfonso F, Macaya C. Platelet aggregation according to body mass index in patients undergoing coronary stenting: should clopidogrel loading dose be weight adjusted? J Invasive Cardiol 2004; 16: 169-74.

10. Reny JL, Berdagué $P$, Poncet $A$, Barazer I, Nolli S, Fabbro-Peray P, Schved JF, Bounameaux H, Mach F, de Moerloose $\mathrm{P}$, Fontana P; Antiplatelet Drug Resistances and Ischemic Events (ADRIE) Study Group. Antiplatelet Drug Resistances and Ischemic Events (ADRIE) Study Group. Antiplatelet drug response status does not predict recurrent ischemic events in stable cardiovascular patients: results of the Antiplatelet Drug Resistances and Ischemic Events study. Circulation 2012; 125: 3201-10.

11. Trenk D, Stone GW, Gawaz M. A randomized trial of prasugrel versus clopidogrel in patients with high platelet reactivity on clopidogrel after elective percutaneous coronary intervention with implantation of drug-eluting stents. Results of the TRIGGER-PCI (Testing Platelet Reactivity In Patients Undergoing Elective Stent Placement on Clopidogrel to Guide Alternative Therapy with Prasugrel) Study. JACC 2012; 59: 2159-64.

12. Collet $S$, Barthélémy $O$, Rangé $G$, Van Belle $E$, Cuisset T, Elhadad S, Schiele F, Lhoest N, Ohlmann $\mathrm{P}$, Carrié $\mathrm{D}$, Rousseau $\mathrm{H}$, Aubry $\mathrm{P}$, Monsequ J, Sabouret P, O'Connor SA, Abtan J, Kerneis M, Saint-Etienne C, Beygui F, Vicaut E, Montalescot G for ARTIC Investigators. Dual-Antiplatelet treatment beyond 1 year after drug-eluting stent implantation (ARTIC-Interruption): a randomised trial. Lancet 2014; 14: 60612-7.

13. Brilakis ES, Patel VG, Banerjee S. Medical management after coronary stent implantation: a review. JAMA 2013; 310: 189-98.

14. Samardzic J, Krpan M, Skoric B, Pasalic M, Petricevic M, Milicic D. Serial clopidogrel dose adjustment after platelet function testing improve outcome of acute coronary syndrome patients undergoing percutaneous coronary intervention with high on-treatment platelet reactivity. J Thromb Thrombolysis 2014; 38: 459-69.

15. Mayer K, Schulz S, Bernlochner I, Morath T, Braun S, Hausleiter J, Massberg S, Schunkert H, Laugwitz KL, Kastrati A, Sibbing D. A comparative cohort study on personalised antiplatelet therapy in PCl-treated patient with high on-clopidogrel platelet reactivity. Result of the ISAR-HPR registry. Thromb Haemost 2014; 112: 342-51.

16. Montalescot G, Rangé G, Silvain J, Bonnet JL, Boueri Z, Barthélémy O, Cayla G, Belle L, Van Belle E, Cuisset T, Elhadad S, Pouillot $C$, Henry $P$, Motreff $P$, Carrié $D$, Rousseau $H$ Aubry $\mathrm{P}$, Monségu J, Sabouret $\mathrm{P}, \mathrm{O}^{\prime}$ Connor SA, Abtan J, Kerneis M, Saint-Etienne C, Beygui F, Vicaut E, Collet JP; ARCTIC Investigators. High on-treatment platelet reactivity as a risk factor for secondary prevention after coronary stent revascularization: A landmark analysis of the ARTIC study. Circulation 2014; 129: 2136-43. 